\section{A representação e a representatividade social do Comitê de Bacia
Hidrográfica dos Rios Vacacaí e Vacacaí-Mirim/RS \\ A representação e a representatividade social do Comitê de Bacia
Hidrográfica dos Rios Vacacaí e Vacacaí-Mirim/RS}

Mara Alini Meier*

Luís Alberto Basso**
Resumo: A participação nos Comitês de Bacia Hidrográfica $(\mathrm{CBH})$ é garantida em lei, mas surgem indagações sobre se ela garante a representação efetiva da sociedade da bacia hidrográfica $(\mathrm{BH})$. Desse modo, com este artigo objetivou-se analisar a representação e representatividade dos representantes do CBH do rio Vacacaí e Vacacaí-Mirim/RS. Neste estudo empregou-se a abordagem metodológica quantitativa, utilizou-se como técnicas de coleta de dados a análise de documentos do $\mathrm{CBH}$ e aplicou-se um questionário estruturado com os representantes do $\mathrm{CBH}$. Os resultados apontaram que a representação do $\mathrm{CBH}$ não abarca de maneira equitativa todos os segmentos envolvidos com os recursos hídricos da $\mathrm{BH}$, porém seus representantes são representativos das suas bases. Foram identificados diversos problemas relacionados a representação e a representatividade social do $\mathrm{CBH}$ que necessitam ser aprofundados.

\section{Representation and social representativeness of the Vacacaí e Vaca- caí-Mirim River Basin Committee/RS}

\begin{abstract}
Participation in River Basin Committees $(\mathrm{CBH})$ is guaranteed by law, but questions about whether it ensures the effective representation of the River Basin $(\mathrm{BH})$ society arise. Thus, this article aims at examining the representation and representativeness of the representatives of the Vacacaí e Vacacaí-Mirim/RS river CBH. This study employed a quantitative approach, using as data collection technique the analysis of $\mathrm{CBH}$ documents and applied a structured questionnaire to the $\mathrm{CBH}$ representatives. The results showed that the representation in $\mathrm{CBH}$ does not cover equitably all segments involved in water resources of the $\mathrm{BH}$, but their representatives represent well their bases. Various issues related to representation and social representativeness in $\mathrm{CBH}$ that need to be deepened.
\end{abstract}

* Mestre em Geografia pela Universidade Federal de Santa Maria (UFSM). Doutoranda em Geografia pela Universidade Federal do Rio Grande do Sul (UFRGS).

** Doutor em Geografia Física e Ordenação do Território pela Universidad de Zaragoza (Espanha). Professor Associado no Departamento de Geografia da UFRGS.

\section{Key-Words:}

Social participation; representation and social representativeness of the CBHs. River Basin Committees of the Vacacaí e Vacacaí-Mirim. 


\section{Introdução}

Com o desenvolvimento da tecnologia que coopera para o desenvolvimento industrial e agropecuário, o crescente processo de urbanização e o aumento da população mundial, verificam-se pressões cada vez maiores sobre os recursos hídricos. Com isso utilizam-se quantidades cada vez mais significativas do recurso para suprir todas as atividades que a sociedade vem desenvolvendo. Associado a isto tem-se o descarte cada vez maior de resíduos que afetam a qualidade das águas. Diante desse quadro, observa-se um processo de degradação ambiental que se amplia cada vez mais, intensificado por um modelo econômico pautado em um consumismo descomunal vigente em grande parte do mundo e no Brasil.

Nesse sentido, a água vem sendo degradada pelas mais variadas fontes de poluição e diversas substâncias. A qualidade e quantidade disponível na natureza vêm diminuindo rapidamente prejudicando ecossistemas, o abastecimento humano e os demais usos que se requer dela.

Os conflitos entre diferentes usos e interesses sobre os recursos hídricos, se expandiram com o passar dos tempos, devido à escassez qualiquantitativa cada vez mais evidente desse recurso (ANA, 2011). Exemplo disso, foram as tensões existentes no Oriente Médio acerca do Rio Jordão (JACOBI, 2008).

Portanto, é necessário observar quais são as formas de organização social adequadas para se enfrentar a degradação crescente das águas e mitigar os conflitos existentes sobre o seu uso. É importante desenvolver um gerenciamento eficaz, isto é, que garanta a qualiquantidade das águas e sua equitativa e justa distribuição (RIBEIRO, 2009).

Nesse contexto, há diversas legislações, fóruns e discussões sobre os recursos hídricos, tanto em nível internacional quanto nacional, que propõem uma gestão e gerenciamento baseados em práticas sustentáveis. Esses aspectos, de cunho teórico, necessitam ser colocados em prática, e para isso se faz necessário verificar quais são os dispositivos legais existentes e como os mesmos estão sendo efetivados.

No Brasil, assim como no Rio Grande do Sul, tem-se a legislação sobre os recursos hídricos, respectivamente a Lei $n^{\circ} 9.433 / 97$ e Lei no 10.350/94. Elas instituem a Política e o Sistema Nacional e Estadual de Recursos Hídricos. Essa nova legislação surgiu para conter uma crise de qualidade e quantidade das águas, decorrente do uso excessivo e mal organizado do recurso (MACHADO, 2003). Essas normas legais encontram-se centradas em um modelo de gestão e gerenciamento integrado, descentralizado e, principalmente, participativo. Os espaços participativos instituídos são os Conselhos de Recursos Hídricos, destacando-se os Comitês de Bacia Hidrográfica (CBHs), locais que estimulam a participação da sociedade na negociação e tomada de decisões referentes aos recursos hídricos da respectiva bacia hidrográfica.

As práticas participativas na gestão dos recursos hídricos ainda são bastante incipientes, mas apontam para uma "nova qualidade de cidadania, que institui o cidadão como criador de direitos para abrir novos espaços de participação sociopolítica" (JACOBI, 2008, p. 14). Além disso, reforçam o significado da publicização das formas de decisão e de consolidação de espaços públicos democráticos. Por isso, os CBHs devem ser reforçados cada vez mais para que estimulem o planejamento, a participação social e a tomada de decisões

Geografia Ensino \& Pesquisa, v. 18, n.3, p. 117-134, set./dez. 2014.

A representação e a representatividade social do Comitê de Bacia Hidrográfica dos Rios Vacacaí e Vacacaí-Mirim/RS

$118 \quad$ ISSN 2236-4994 que visem ao uso sustentável dos recursos hídricos e ao interesse comum.

Somente a garantia legal dos $\mathrm{CBHs}$ não assegura que eles estejam atingindo seus objetivos. Não se pode perder de vista que a participação é, em si, um "conceito e uma prática em disputa" (SANTOS e SAITO, 2006, p.9). Diante disso, dependendo de como a participação social é conduzida e se efetiva pode levar à sua mitificação.

A participação social que ocorre nos CBHs necessita de profundas análises, pois ela deve garantir que os anseios da sociedade sejam levados em conta no processo de decisão. 
Nesses espaços, são os representantes de determinadas categorias, os responsáveis por trazer os interesses das suas bases para o processo decisório. Por isso a representação e a representatividade dos representantes que compõem os $\mathrm{CBHs}$ merecem atenção especial. Dessa forma, para que as reflexões sobre os $\mathrm{CBHs}$ avancem é necessário estruturar pesquisas que compreendam as barreiras, os entraves e as problemáticas que permeiam as atividades dessas instâncias, para que se consiga estabelecer alternativas e meios de superá-los.

Atualmente, na nova agenda da geografia política, devem ser incluídas novas questões que se apresentam nas relações entre a sociedade e seus espaços políticos. Entre eles os "conflitos distributivos emergem como uma questão geográfica e definem um campo temático que orienta o olhar para os atores sociais cujos interesses e ações moldam e são moldados por recortes espaciais aos quais esses atores atribuem valores materiais e simbólicos" (CASTRO, 2005).

Conforme Santos (1999, p.51), o espaço geográfico é "um conjunto indissociável, solidário e também contraditório, de sistemas de objetos e sistemas de ações". Na área de recursos hídricos os planejamentos e as ações são definidos nos CBHs. Ali, regula-se a relação da sociedade com os recursos hídricos, que também se reflete na (re)organização do espaço geográfico. Por isso, a análise de como se estruturam esses espaços, quem participa e como tomam as decisões são aspectos importantes para a compreensão de como os recursos hídricos serão utilizados e como isso se refletirá sobre o espaço geográfico.

Diante disso, centra-se na seguinte questão: "os CBHs representam efetivamente a sociedade da bacia hidrográfica?". Com isso, neste artigo tem-se o objetivo de analisar a representação e a representatividade dos representantes do $\mathrm{CBH}$ dos rios Vacacaí e Vacacaí-Mirim (CBH V-VM) a fim de verificar se a sociedade participa realmente da tomada de decisões dentro dos CBHs. Isso se torna relevante, pois permite compreender como esses aspectos interferem nas decisões e ações desses ambientes, e por sua vez como atuam sobre o espaço geográfico.

\section{A governança e o processo participativo dos recursos hídricos}

O conceito de governança foi criado em 1980 voltado à gestão pública, referindo-se ao desempenho governamental e à relação do Estado com os cidadãos e com suas reivindicações. Reportava-se, ainda, à atuação da sociedade civil como capaz de refazer sua interação com o Estado e o mercado nos processos decisórios, tentando reverter as relações hierárquicas em participativas (GRANJA, 2008; VALÊNCIO, 2009). Esse conceito pode também ser compreendido como:

\footnotetext{
A governança consistiria no estabelecimento de um sistema de normas inseridas em um redesenho estratégico que envolve a participação de variados atores sociais - ONGs, associações, mercado - que compartilham da capacidade governativa do Estado, na identificação dos problemas da sociedade e na formulação de políticas públicas e na sua implementação (GRANJA, 2008, p.1).
}

A governança é um estilo de governo democrático caracterizado por um compartilhamento de atribuições entre o Estado e a sociedade, baseando-se em um modelo representativo. Nesse ambiente, as políticas são construídas coletivamente e sem imposição; os resultados são provenientes da negociação e do consenso, onde cada ator tem direito a se manifestar, compondo um processo de interdependência coletiva. A governança envolve um processo complexo baseado na participação multi-setorial de agentes públicos e privados, usuários e sociedade. Diante disso, a boa governança envolve o planejamento e a construção política em um processo participativo (MOREIRA et al, 2013).

Geografia Ensino \& Pesquisa, v. 18, n.3 p. $117-134$, set./dez. 2014

Meier, M.A.; Basso, L. A.

ISSN 2236-4994 119 
Ribeiro (2009) salienta que a governança implica em reunir pessoas para discutir um tema complexo e que representem o Estado e a sociedade civil, onde:

(...) a presença da sociedade civil seria a causa primeira da governança, dividiria atribuições com o Estado, mas também o pressionaria a adotar políticas públicas compatíveis com os seus interesses. O resultado seria uma teia de relações políticas que mobiliza atores estatais por meio de diversos órgãos, mais representantes da sociedade civil organizada, sejam sindicatos patronais, de trabalhadores e de outros segmentos sociais. Pode-se até mesmo institucionalizar essa prática, como se verifica no Brasil por meio dos comitês de bacia hidrográfica (RIBEIRO, 2009, p. 117).

Ainda, a governança compõe:

a noção de poder social que media as relações entre Estado e sociedade civil, como espaço de construção de alianças e cooperação, mas também permeado por conflitos que decorrem do impacto das assimetrias sociais e seus impactos no meio ambiente e das formas de resistência, organização e participação dos diversos atores envolvidos (JACOBI, 2009, p.40).

A governança na gestão das águas aparece na agenda política e acadêmica contemporânea a partir da lei federal n ${ }^{\circ} 9.433 / 97$, "como um constructo representacional de grande e crescente aceitação por evocar uma nova estrutura de poder, imbuída de novos sujeitos e práticas, configurando-se num processo político renovador" (VALÊNCIO, 2009, p.61).

No contexto da gestão hídrica a governança, como arcabouço conceitual, representa um enfoque que propõe caminhos teóricos e práticos alternativos que articulem as demandas sociais com o nível governamental. O conceito envolve leis, regulação e instituições, e também políticas e ações de governo, até iniciativas locais e redes de influência entre os mais variados atores (JACOBI, 2009).

A governança da água deve ser caracterizada pela responsabilidade social, transparência, participação e descentralização na tomada de decisões. Ela compõe um processo de construção e reforma na relação do governo com a sociedade (MOREIRA et al, 2013), em que a negociação, a comunicação e a confiança seriam necessárias, e os atores públicos, comunitários e privados cooperariam para o bem da coletividade. As arenas decisórias de pequena escala seriam valorizadas; a interação do cidadão e do Estado teriam maior efetividade; a identificação dos sujeitos envolvidos na disputa pela água se tornaria mais fácil; haveria o compartilhamento conjunto dos desafios, do acompanhamento e da avaliação das soluções estabelecidas. Além disso, torna oportuna a verbalização das demandas (empoderamento) e a fiscalização das decisões (accountability) (VALÊNCIO, 2009).

Em suma, a governança das águas abrange aspectos como: uma nova relação entre Estado e sociedade; participação de diversos atores sociais; negociação dos conflitos para alcançar consensos; acomodação de interesses conflitantes; compartilhamento de poder decisório em condições igualitárias; cooperação para o bem coletivo, entre outros.

Para que a governança das águas se efetive, é necessário que haja a consolidação da participação da sociedade no trato das questões que envolvem os recursos hídricos. O processo participativo decorrente tem como finalidade democratizar a gestão das águas incluindo os segmentos envolvidos. De acordo com a legislação de recursos hídricos deve haver o envolvimento da sociedade, do Estado e dos usuários da água na tomada de decisões sobre esse recurso, integrando esses atores em espaços participativos institucionalizados, como os Conselhos de Recursos Hídricos e os CBHs.

Geografia Ensino \& Pesquisa, v. 18, n.3, p. $117-134$, set./dez. 2014

A representação e a representatividade social do Comitê de Bacia Hidrográfica dos Rios Vacacaí e Vacacaí-Mirim/RS
Em sentido amplo, a participação é compreendida por Teixeira (1997, p.187) como "fazer parte, tomar parte, ser parte de um ato ou processo, de uma atividade pública, de ações coletivas". Já Modesto (1999) define a participação como a intervenção em um processo decisório qualquer. Santos e Saito (2006) e Arnstein (1969) remetem a participação a algo ativo, às disputas pelo poder e sua distribuição entre os atores envolvidos. Nesse sentido, para que a participação se efetive é necessária uma verdadeira distribuição de poder entre os atores sociais (SANTOS; SAITO, 2006). 
Teixeira (1996) frisa que a participação deve proporcionar um poder compartilhado, com co-responsabilidades e respeito à autonomia da organização dos membros e/ou grupos envolvidos. Font et al. (2000) argumentam que a participação dos cidadãos em diferentes instâncias participativas deve preservar, como também potencializar a capacidade de representação do conjunto de interesses dos distintos cidadãos e grupos sociais nas decisões públicas.

Demo (2001, p. 18) define que "participação é conquista", no sentido de processo, sendo "infindável, em constante vir a ser, sempre se fazendo". Para tanto, ela não pode ser compreendida como uma dádiva, como concessão, como algo pré-existente, mas como um processo que precisa ser construído. Diante disso, a participação não pode ser vista como um fim em si mesma, mas como um processo que implica em uma relação de poder entre os atores envolvidos nela. Portanto, deve-se permanecer atento à real finalidade a que se presta a participação, podendo ser meramente comunicativa e consensual ou possuir uma concepção estratégica.

Acrescenta-se ainda o disposto por Santos e Saito (2006, p. 9), que afirmam que "a participação é, em si, um conceito e uma prática em disputa". Assim, dependendo de como a participação social é conduzida e se efetiva pode levar-se à sua mitificação. Por isso, ainda há muito a ser estudado sobre os processos participativos, a fim de observar suas problemáticas e apontar soluções que possam dinamizar e torná-los mais democráticos. Dessa maneira, contribui-se para que todas as vozes sejam ouvidas e que ocorra uma verdadeira partilha de poder decisório entre os atores sociais envolvidos.

\section{A governança e o processo participativo dos recursos hídricos}

Com a nova legislação de recursos hídricos, Lei no 9.433/97, foram criados os Comitês de Bacia Hidrográfica. Eles são considerados como parlamentos das águas, nos quais deve ocorrer um processo decisório com participação dos diferentes atores envolvidos com os recursos hídricos da bacia hidrográfica $(\mathrm{BH})$. Nos $\mathrm{CBHs}$ desenvolve-se um processo de tomada de decisões sobre um bem público: os recursos hídricos. Por isso, essas instâncias devem possuir uma representação democrática, onde haja ampla participação dos diferentes atores sociais, onde ocorra uma co-decisão e co-gestão do recurso água, voltada ao interesse coletivo.

Em espaços participativos o processo de tomada de decisão envolve dois aspectos: o sujeito (atores que tomam as decisões) e o processo decisório (como isso acontece) (TEIXEIRA, 1997).

No tocante aos sujeitos envolvidos, quando se trata da gestão participativa das águas, destaca-se a importância da participação da sociedade na definição das políticas públicas, programas e projetos de gestão. A participação social contribui para a democratização desse processo, além de permitir que a sociedade seja co-responsável, legitime, acompanhe e exija o cumprimento dos planejamentos coletivos pelas instâncias competentes. Assim, prevalecerão os interesses da coletividade ao invés dos particulares de setores econômicos ou do setor governamental (FRACALANZA, 2009, p. 151). Além disso, a participação da sociedade faz-se necessária porque é ela quem sofre, direta ou indiretamente, com a degradação ambiental e com as suas consequências.

O processo participativo de gestão das águas não depende apenas da participação da sociedade, mas dos demais stakeholders nesse processo, pois para que um CBH cumpra seu papel, a colaboração entre todos os atores é o caminho mais promissor (FRANK, 2010). Desta maneira:

Trata-se de democratizar a gestão dos recursos hídricos, de compartilhar o poder de decidir, e isto requer do poder público determinação para dividir poder e dos usuários e da sociedade civil, a determinação para compartilhar responsabilidades (ANA, 2011, p.19).

Geografia Ensino \& Pesquisa, v. 18, n.3 p. 117-134, set./dez. 2014.

Meier, M.A.; Basso, L. A. 
É necessário que cada sujeito envolvido no processo participativo entenda seu papel, suas responsabilidades e atribuições, bem como estabeleça canais de comunicação com suas bases e com os demais sujeitos do processo para que sua participação seja legítima. Nesse contexto, o representante deve estar preparado para defender os interesses do segmento que representa (ANA, 2011; LEAL, 2003).

Existe a necessidade de uma melhor avaliação do alcance desses espaços participativos, observando a sua composição, a atuação dos atores envolvidos, a sua legitimidade junto às suas bases e os resultados alcançados pelos mesmos. Por isso, defende-se a necessidade da análise da representação e da representatividade dos membros do $\mathrm{CBH}$ nesses espaços. Com isso, tem-se a finalidade de contribuir com a superação dos impasses apresentados e promover o avanço da governança da água e da participação social em instâncias participativas de gestão e de gerenciamento dos recursos hídricos, além de contribuir com a compatibilização dos interesses e com a conciliação das demandas pela água.

\section{A representação e a representatividade dos representantes dos $\mathrm{CBHs}$}

${ }^{1}$ Como mencionado acima, será utilizado o termo membro para a instituição ou organismo com assento no $\mathrm{CBH}$, e representante de um membro é a pessoa que por ele for credenciada junto ao $\mathrm{CBH}$ (RS, 1996).

Geografia Ensino \& Pesquisa, v. 18, n.3, p. 117-134, set./dez. 2014.

A representação e a representatividade social do Comitê de Bacia Hidrográfica dos Rios Vacacaí e Vacacaí-Mirim/RS
A representação nos $\mathrm{CBHs}$ existe quando alguém dá poder a outra pessoa para representá-la. Assim, podemos definir a representação como "ato pelo qual alguém é legalmente autorizado a agir em nome de outrem” (MELHORAMENTOS, 2012, s/p.). A representação pode ser entendida como o ato de substituir determinado grupo, segmento ou indivíduo na defesa de seus interesses gerais. Nesse sentido, Pitkin (1967) definiu representação política como uma relação que conecta representantes e representados. O representante possui legitimidade em função de sua autorização e prestação de contas aos representados, respondendo aos anseios daqueles que representa. Leal (2003) adverte que essa relação, para ser democrática, deverá ser desenvolvida de maneira visível e transparente, garantindo a legitimidade da representação.

Espaços participativos, como os Conselhos de Políticas Públicas e os CBHs, possuem estrutura semelhante e são compostos por representantes. Esses representantes se encontram em nome de diversos segmentos sociais e estruturam a representação desse espaço.

A representação dos espaços participativos deve garantir que todos os interesses e visões dos atores sociais estejam representados de forma equilibrada no processo de tomada de decisões, democratizando o processo. Para que isso ocorra, a representação deve ser: plural, com o intuito de assegurar a heterogeneidade dos atores que se envolvem com a questão em debate; significativa para a base representada; equânime, em que os diversos atores tenham a possibilidade de participar de forma igualitária; distribuída socialmente, sem a estruturação de pólos de poder político. E, ainda, é importante que os representantes ocupem as vagas disponíveis e se façam presentes nas reuniões, além de participarem ativamente das discussões. Se todos esses aspectos se concretizarem, será possível estruturar uma representação que garanta a igualdade de direitos entre os atores na sua participação, distribuindo igualmente o poder de decisão.

Nesse sentido, compreende-se a representação do CBH em dois momentos:

$1^{\circ}$ Momento: A representação dos stakeholders (por setor e por categoria) compondo os membros $^{1}$ da plenária do $\mathrm{CBH}$.

$2^{\circ}$ Momento: os representantes escolhidos pelos membros do $\mathrm{CBH}$.

Esses dois momentos são influenciados por vários fatores (como veremos no presente artigo).

A representação equitativa por si só não garante uma participação democrática, porém é o primeiro passo para que ela ocorra. É necessário agregar à representação um outro elemento: a representatividade dos sujeitos no processo participativo. 
Compreende-se a representatividade como a "qualidade da representação entre o representante e o segmento social para quem está dirigida a representação" (NEDER, 2002, p. 201), acrescenta-se a "qualidade de alguém (representante) expressar os interesses de um grupo, o qual ele represente e que possa exprimir não somente a sua opinião individual, mas a do conjunto de pessoas" (ANA, 2011, p.35).

Nesse sentido o representante, para que seja representativo deve conhecer, defender e encaminhar para a discussão, nos espaços participativos, os interesses e demandas da base que representa, isto é, interesses coletivos (LEAL, 2003). Diante disso, devem intervir nos espaços participativos como mediadores, encaminhando as demandas da base. Para isso os representantes devem apresentar uma interação significativa com a base, possuir engajamento no processo participativo e dispor de características que os capacitem a defender os interesses e as opiniões da base, proporcionando uma partilha de poder decisório.

A representatividade dos representantes do $\mathrm{CBH}$ é compreendida em dois momentos distintos:

$1^{\circ}$ momento: a representatividade dos membros do $\mathrm{CBH}$ em nome dos interesses da sociedade, dos usuários ou do poder público envolvidos com as águas na $\mathrm{BH}$.

$2^{\circ}$ momento: a representatividade dos representantes em exprimir os interesses da sua instituição de origem ${ }^{2}$. E para que isso aconteça vários fatores intervém nesse processo, como:

a) A capacidade que o representante tem de articular-se com a sua base, possuindo as seguintes finalidades: colher opiniões, sugestões e posicionamentos para serem levados às reuniões do CBH, garantindo os interesses dessa base no processo de tomada de decisões (LEAL, 2003); e divulgar às suas bases as informações e decisões emanadas do CBH.

b) Qualidades individuais dos representantes e os recursos disponíveis para participar, como: a experiência que possui sobre a gestão dos recursos hídricos, conhecimento sobre a $\mathrm{BH}$, a qualificação técnica e política dos representantes, conhecimento sobre o funcionamento do $\mathrm{CBH}$, engajamento dos representantes na participação, entre outros.

c) A capacidade de articulação do representante com os demais representantes no $\mathrm{CBH}$.

Destarte, a representação e a representatividade dos representantes do $\mathrm{CBH}$ devem possibilitar que todos os segmentos da sociedade estejam presentes e tenham as mesmas condições de intervir no processo decisório do $\mathrm{CBH}$. Porém, se a representação e representatividade privilegia algum setor este, por sua vez, tem seus interesses garantidos, enquanto os demais são negligenciados. Essas ações e decisões irão privilegiar parte dos interesses envolvidos com os recursos hídricos, tornando-se pouco democrático. Por sua vez essas decisões e ações irão afetar o modo como utilizam-se os recursos hídricos e também (re)organizam o espaço geográfico.

\section{Metodologia}

O presente artigo possui como objetivo analisar a representação e a representatividade dos representantes do CBH V-VM, a fim de verificar se a sociedade participa realmente da tomada de decisões dentro dos $\mathrm{CBHs}$, identificando os problemas desse processo.

A abordagem metodológica empregada nesta pesquisa é quantitativa. Ela se fundamenta no pensamento dedutivo; define variáveis de pesquisa e examina as relações entre as mesmas; se atém à medição numérica; tem a pretensão de generalizar os resultados através de amostras representativas (NEVES, 1996; FREITAS et al., 2000; TERENCE; FILHO, 2006; SAMPIERI et al, 2006).

O tipo de pesquisa a ser empregado será o survey (levantamento), que é a obtenção de
${ }^{2}$ Somente este momento será tratado no presente artigo.
Geografia Ensino \& Pesquisa, v. 18, n.3 p. 117-134, set./dez. 2014.

Meier, M.A.; Basso, L. A. 
dados ou informações sobre características de um grupo de pessoas, objetivando produzir descrições quantitativas, mediante um instrumento de pesquisa (FREITAS et al., 2000). As técnicas de coleta de dados empregadas serão a análise de documentos do $\mathrm{CBH}$, como a listagem de seus membros e representantes, e a aplicação de um questionário estruturado com questões fechadas com os representantes titulares e suplentes do $\mathrm{CBH}$. O tratamento dos dados será quantitativo mediante cálculos de frequência das respostas obtidas, empregando porcentagem. Os indicadores utilizados para a análise da representação e da representatividade dos representantes do CBH podem ser vistos na Figura 1 a seguir:

Figura 1 - Localização de Buritizeiro na mesorregião Norte de Minas.
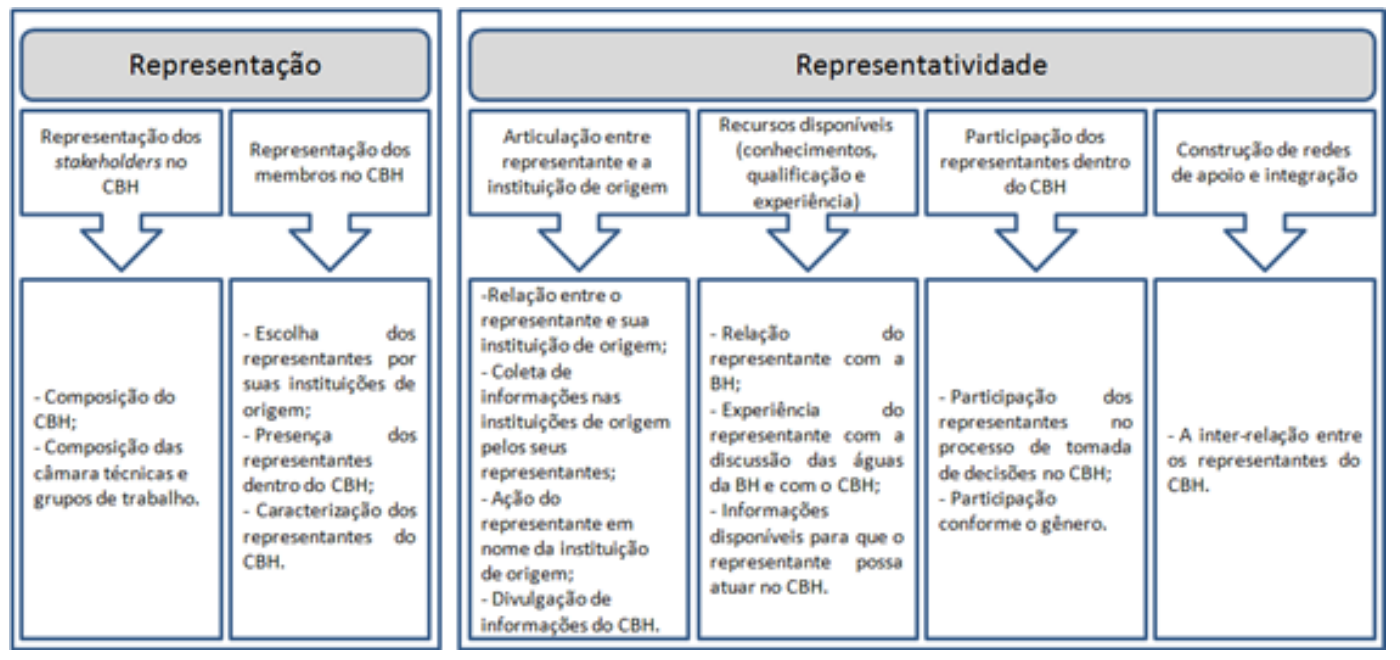

Fonte: elaborado pelos autores.

3 A legislação estadual de recursos hídricos $\mathrm{n}^{\circ}$ 10.350/94 define que os $\mathrm{CBHs}$ serão compostos por três segmentos: Categoria dos usuários da água possuirá $40 \%$ das vagas, Categoria população da bacia hidrográfica possuirá $40 \%$ das vagas e Categoria do poder público com $20 \%$ das vagas do $\mathrm{CBH}$.

Geografia Ensino \& Pesquisa, v. 18, n.3, p. $117-134$, set./dez. 2014

A representação e a representatividade social do Comitê de Bacia Hidrográfica dos Rios Vacacaí e Vacacaí-Mirim/RS
O questionário foi aplicado no dia 08 de novembro de 2013 em reunião ordinária do $\mathrm{CBH}$. Os membros que não estiveram presentes na reunião receberam o formulário de perguntas por e-mail, encaminhados pela secretária executiva do $\mathrm{CBH}$.

\section{Resultados}

Representação do CBH dos rios Vacacaí e Vacacaí-Mirim

O CBH é composto de 35 vagas para membros titulares, sendo 14 vagas $(40 \%)$ para os usuários, 14 vagas (40\%) para a população da bacia e 7 vagas (20\%) para o poder público Estadual e Federal. Cada vaga de titular possui uma vaga de suplente. Dessa forma, a composição do $\mathrm{CBH}$ cumpre com o disposto pela legislação estadual de recursos hídricos ${ }^{3}$, garantindo uma divisão harmônica dos votos entre os setores representados nessa instância e assegurando uma presença equilibrada dos diferentes interesses no processo decisório.

No entanto, ao analisar as vagas titulares realmente ocupadas pelos membros, observa-se que no total 27 estão ocupadas $(77 \%)$. Das vagas preenchidas 12 são ocupadas pelos usuários da água (44\%), 12 pela população da BH (44\%) e 3 pelo poder público (11\%). Dos 27 membros, 25 indicaram nomes de representantes para ocupar as suas vagas. Um membro da população da BH e um do poder público não indicaram representantes, consequentemente não ocupam suas respectivas vagas. Assim, a composição do $\mathrm{CBH}$ muda para: usuários 12 vagas (48\%), população 
da BH 11 vagas (44\%) e poder público 2 vagas (8\%) preenchidas. Dessa forma, observa-se que a representação do $\mathrm{CBH}$ não cumpre o estabelecido pela legislação estadual de recursos hídricos, sendo que o setor dos usuários da água possui a maior representação e o setor do poder público encontra-se quase sem representação no $\mathrm{CBH}$.

Os dados sugerem que o setor da população da $\mathrm{BH}$, que tradicionalmente encontrava-se excluída do processo de tomada de decisões, permanece em desvantagem nesse processo, pois possui representação menor do que o setor dos usuários da água no $\mathrm{CBH}$. Os usuários da água e o poder público eram os tradicionais detentores de influência sobre as decisões de gabinete sobre as águas. Nota-se que os usuários da água permanecem como os principais tomadores de decisão dentro do $\mathrm{CBH}$ e o poder público quase não possui representação, praticamente não participando dessa instância. Com isso, pode-se dizer que não existe uma representação equitativa dos diferentes stakeholders e de seus interesses no processo de tomada de decisões sobre as águas na $\mathrm{BH}$, consequentemente não ocorre uma efetiva partilha de poder entre eles no $\mathrm{CBH}$.

A composição dos suplentes é a mesma dos titulares, pois cada titular possui o seu suplente. Uma das estratégias utilizadas para preencher as vagas de suplência é a entidade membro, que já possui a vaga de titular, pleitear a respectiva vaga de suplência. Isso ocorre em $92 \%$ do setor dos usuários da água, $83 \%$ do setor da população da $\mathrm{BH}$ e em $67 \%$ do setor do poder público. Diante dessa estratégia observa-se a redução da diversidade sociopolítica na composição do $\mathrm{CBH}$, dificultando a representação dos vários grupos sociais e dos interesses envolvidos na questão das águas.

A legislação estadual de recursos hídricos define que os municípios devem compor o setor da população da BH. Entretanto, no CBH V-VM não existem vagas destinadas a essa categoria nesse setor, não cumprindo a legislação. Porém, pode-se notar que o setor da população da $\mathrm{BH}$ está representada apenas por entidades da população. As prefeituras encontram-se representadas apenas no setor dos usuários, nas categorias de abastecimento público, esgotamento sanitário e drenagem, totalizando 4 vagas ocupadas, o equivalente a $15 \%$ das vagas do $\mathrm{CBH}$.

Quanto à participação dos representantes em instâncias dentro do $\mathrm{CBH}$, como as Câmaras Técnicas (CTs) e Grupos de Trabalho (GTs), verifica-se que poucos representantes possuem participação nas mesmas, respectivamente $17 \%$ e $8 \%$ do total de representantes participam das mesmas. Entre os representantes presentes nas CTs, 25\% são do setor da população da BH e $14 \%$ são do setor dos usuários da água. Todos os representantes que compõem os GTs pertencem ao setor dos usuários da água. O setor do poder público não participa dessas instâncias.

Essas instâncias são estratégicas dentro do $\mathrm{CBH}$, pois possuem a função de apoiar a tomada de decisões desse espaço, porém poucos representantes compreendem a importância das mesmas. Observa-se que o setor da população da $\mathrm{BH}$ possui maior poder sobre as atividades das CTs, e o setor dos usuários da água controlam os GTs. Assim, essas instâncias não representam igualmente os setores do $\mathrm{CBH}$, podendo ser consideradas como ferramentas de manipulação do $\mathrm{CBH}$ por alguns grupos, garantindo interesses particulares e não coletivos.

Ao analisar o perfil dos representantes teve-se como objetivo verificar se a representação do $\mathrm{CBH}$ é plural e distribuída socialmente, características que revelam a natureza pública e democrática desses espaços. As características analisadas foram o gênero, a idade, a renda mensal e o nível de formação dos representantes. A partir das respostas obtidas verificou-se que existe uma diversidade importante das características observadas, pois o CBH está composto por homens e mulheres, representantes com idades entre 20 e 60 anos, renda mensal que varia de um a 20 salários mínimos e formação que se estende do fundamental incompleto a pós-graduação. No entanto, identificou-se uma concentração de representantes do sexo masculino (75\%), idade superior aos 40 anos (67\%), renda mensal superior aos cinco salários mínimos $(75 \%)$ e formação em nível superior (83\%), onde 58\% possuem nível de pós-graduação. Diante disso, nota-se que existe polarização do perfil dos representantes, o que não garante a representação equitativa de todos os grupos sociais no processo de negociação sobre as águas no $\mathrm{CBH}$.

Geografia Ensino \& Pesquisa, v. 18, n. 3 p. $117-134$, set./dez. 2014

Meier, M.A.; Basso, L. A. 
Entre os representantes do CBH 75\% são homens e 25\% são mulheres. A composição mais desigual encontra-se no setor dos usuários da água, em que os homens (85\%) possuem representação superior a média do $\mathrm{CBH}$. Já a representação de homens e mulheres no setor da população da $\mathrm{BH}$ segue a média do $\mathrm{CBH}$. E no setor do poder público ocorre o inverso, as mulheres $(68 \%)$ são maioria na sua composição. Pode-se constatar que a representação do $\mathrm{CBH}$ não inclui em proporção igualitária homens e mulheres. Assim, os diferentes olhares e identidades não são levados igualmente em consideração no momento da discussão das águas, não possibilitando uma efetiva partilha de poder entre eles nesse processo.

Das vagas de titular ocupadas no $\mathrm{CBH}$, pode-se observar que $68 \%$ delas são ocupadas por homens e $32 \%$ por mulheres. Com isso, constata-se o papel secundário que as mulheres exercem dentro dos $\mathrm{CBHs}$, não tendo influência significativa sobre a tomada de decisões nessa instância, enquanto que os homens detêm esse poder.

A idade dos representantes concentra-se na faixa acima dos 40 anos (67\%). O setor dos usuários da água possui $57 \%$ dos seus representantes com idade acima dos 50 anos, o setor da população da $\mathrm{BH}$ têm $50 \%$ dos seus representantes com idade entre 40 e 50 anos e 100\% dos representantes do setor do poder público apresentam idade entre 30 e 40 anos. Os mais jovens representantes, entre 20 e 30 anos de idade encontram-se em pequena porção nos setores da população da $\mathrm{BH}(25 \%)$ e dos usuários da água (14\%). Esses dois setores apresentam a maior diversidade de faixas de idade, indo desde os 20 anos até os 60 anos.

A renda mensal dos representantes concentra-se acima dos cinco salários mínimos (75\%). A margem entre cinco e dez salários mínimos é a mais expressiva nos três setores, onde o setor do poder público possui $100 \%$, o setor dos usuários têm $71 \%$ e o setor da população da BH apresenta $50 \%$ dos seus representantes com essa margem de renda. Porém os maiores salários (entre dez e 20 salários) encontram-se no setor da população da BH em pequena porção (25\%). A representação do $\mathrm{CBH}$ é formada principalmente pela classe social mais alta, que controla as atividades do $\mathrm{CBH}$, enquanto que os segmentos da sociedade que são desprivilegiados economicamente encontram-se praticamente excluídos da discussão e da tomada de decisões sobre as águas nos $\mathrm{CBHs}$.

O nível de formação dos representantes é alto e possui expressão significativa no nível de ensino superior $(83 \%)$, principalmente nos setores do poder público $(100 \%)$ e dos usuários da água $(86 \%)$. O setor dos usuários também possui a menor formação existente (fundamental incompleto) com 14\%. Dos representantes que possuem nível superior, $80 \%$ possuem pós-graduação (entre completa e incompleta). O nível de pós-graduação é mais expressivo nos setores do poder público $(100 \%)$ e da população da BH (75\%). Pode-se verificar que o grupo dos usuários possui a maior diversidade de níveis de formação, indo do ensino fundamental até a pós-graduação.

Em suma, a partir da análise do perfil dos representantes pode-se dizer que a representação do $\mathrm{CBH}$ é bastante heterogenia. No entanto, ela não é distribuída socialmente, pois concentra-se em alguns grupos sociais, não podendo ser considerado um espaço efetivamente democrático. Os grupos com maior representação dentro do CBH são: os homens, a classe social de maior poder aquisitivo, pessoas com nível de formação elevada e idade maior. E os grupos com menor representação são: as mulheres, os jovens e pessoas com nível de renda e instrução baixos. Nota-se que o CBH reproduz as desigualdades e exclusões presentes na sociedade brasileira, constituindo um espaço de fortalecimento dessas desigualdades sociais.

Ao analisar a presença dos representantes no $\mathrm{CBH}$ observou-se que $58 \%$ deles participam de todas as reuniões do $\mathrm{CBH} .100 \%$ dos representantes do setor da população da $\mathrm{BH}$ afirmaram comparecer a todas as reuniões. Entre os representantes do setor dos usuários da água $57 \%$, e do setor do poder público 100\%, afirmaram não participar de todas as reuniões. Os representantes do setor da população da BH são os mais assíduos nas reuniões, conseguindo defender seus interesses de forma mais eficiente do que os representantes dos outros setores, que possuem menor 
presença dentro dessa instância. Dessa maneira, os representantes do setor da população da BH ao estarem mais presentes nas plenárias conseguem acompanhar todo o processo de negociação e intervir em maior número de decisões, assim possuem uma representação mais significativa.

Os representantes apresentaram como principal justificativa para as suas faltas nas reuniões do CBH: os compromissos profissionais (43\%). Essa justificativa teve nos setores dos usuários $50 \%$ e na população da $\mathrm{BH} 40 \%$ das respostas. A segunda justificativa mais expressiva, com $14 \%$ das respostas, foi a pauta das reuniões com assuntos pouco interessantes, que desmotiva os representantes a comparecerem às reuniões do $\mathrm{CBH}$. No setor da população da $\mathrm{BH} 20 \%$ e no setor dos usuários da água 12\% dos representantes apontaram essa resposta. No setor do poder público foi apontada a questão do representante ser suplente como único motivo para a falta nas reuniões. A incompatibilidade entre compromissos profissionais e reuniões do $\mathrm{CBH}$ ocorre principalmente porque elas acontecem em horário comercial. Uma das possibilidades para solucionar esse problema seria realizar as reuniões em horário alternativo, que não coincidisse com o horário de trabalho dos representantes. Com isso, seria possível aumentar a freqüência dos representantes e agregar maior número de pessoas às reuniões do $\mathrm{CBH}$.

Todos os representantes moram na $\mathrm{BH}$ onde se localiza o $\mathrm{CBH}$. Dos 14 municípios pertencentes a BH apenas três (21\%) encontram-se representados: Santa Maria, São Sepé e Itaara. Observa-se que a distribuição geográfica dos representantes sobre a BH não é uniforme, havendo concentração em municípios que se encontram no centro da $\mathrm{BH}$ (no sentido norte-sul). A maior concentração ocorre no município de Santa Maria, com 75\% (local onde sempre ocorrem as reuniões), São Sepé com 17\% e Itaara com 8\% dos representantes. Somente Santa Maria possui representantes dos três setores, onde os usuários da água possuem $67 \%$, população da $\mathrm{BH} 22 \%$ e poder público $11 \%$ dos representantes. Itaara possui somente representantes do setor da população da $\mathrm{BH}$ e São Sepé possui representantes dos usuários da água e da população da $\mathrm{BH}$ com $50 \%$ cada um. Na Figura 2 pode-se verificar a distribuição dos representantes pelos municípios da $\mathrm{BH}$ e os setores a que pertencem no $\mathrm{CBH}$.

Figura 2 - Representantes do CBH V-VM por município de residência e por setores do CBH.

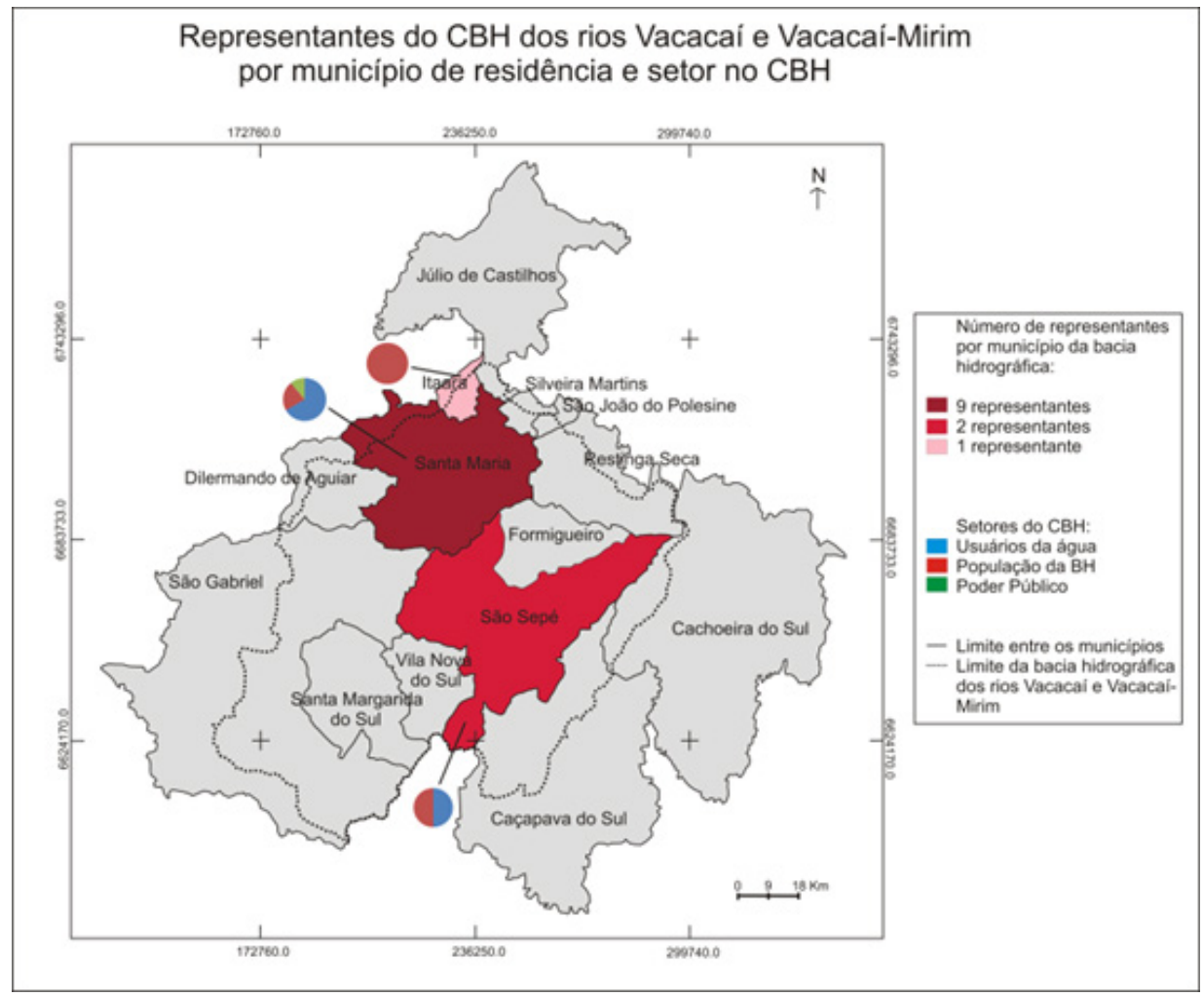

Geografia Ensino \& Pesquisa, v. 18, n. 3 p. $117-134$, set./dez. 2014

Meier, M.A.; Basso, L. A.

Fonte: elaborado pelos autores. 
Em resumo, pode-se destacar que a representação do $\mathrm{CBH}$ possui diversas problemáticas, entre as principais estão: a falta de cumprimento prático das prerrogativas da legislação estadual de recursos hídricos sobre a composição dos $\mathrm{CBHs}$; falta de equidade na representação dos setores na composição do CBH e nas CTs e GTs; concentração do perfil dos representantes em alguns grupos sociais; e a totalidade da $\mathrm{BH}$ não se encontra representada no $\mathrm{CBH}$. Entre os setores são os usuários da água e a população da BH que possuem uma representação mais efetiva dentro do $\mathrm{CBH}$, enquanto o setor do poder público possui a representação mais tímida dentro dessa instância.

Concluí-se que a representação do $\mathrm{CBH}$ não inclui todos os stakeholders de forma equilibrada no processo decisório sobre as águas, o que leva a caracterização como um espaço pouco democrático. Nesse sentido, é necessário estruturar estratégias para resolver os problemas que a representação desse espaço apresenta, para que todos os atores sociais estejam igualmente representados e tenham os seus interesses garantidos no processo decisório sobre as águas da $\mathrm{BH}$.

Representatividade dos representantes do CBH dos rios Vacacaí e Vacacaí-Mirim

Para que os representantes sejam representativos e possam atuar como verdadeiros representantes das entidades de origem é necessária a estruturação de vias de comunicação entre representantes e representados. Dessa forma, o representante conhece os interesses e as demandas dessa base para que possa defendê-los no CBH. A base fica sabendo o que acontece no $\mathrm{CBH}$, pode expressar a sua opinião a respeito do que vem sendo discutido nessa instância e controla a ação de seu representante. Permite ainda aos representantes colher opiniões e construir posições junto à base sobre assuntos do $\mathrm{CBH}$, e prestar contas da sua ação dentro dessa instância. Nota-se que no CBH essa interação ocorre entre representantes e entidades de origem, porém com ressalvas quanto à efetiva representação dos interesses da base no $\mathrm{CBH}$.

Todos os representantes possuem interação com sua instituição de origem para tratar de assuntos vinculados ao CBH. Os principais motivos para que eles estabeleçam essa relação se deve a: construção de posições junto à entidade de origem para ser utilizada nas discussões do $\mathrm{CBH}(35 \%)$ e para a divulgação de informações do $\mathrm{CBH}$ à entidade de origem (35\%). Os representantes do setor dos usuários da água (30\% para cada um) e os representantes do setor da população da $\mathrm{BH}$ (respectivamente $50 \%$ e $33 \%$ ) apontam esses dois motivos como os mais expressivos, os representantes do setor do poder público tem como único motivo a divulgação de informações do CBH para a entidade de origem.

O principal canal de comunicação utilizado para esse contato é a conversa informal do representante com pessoas que fazem parte da entidade de origem (57\%). A utilização desse canal é expressivo entre os representantes do setor dos usuários da água (71\%) e entre os representantes do setor da população da $\mathrm{BH}(50 \%)$, já o poder público utiliza como único meio de interação a conversa informal com a presidência da entidade. Constata-se que a interação entre representantes e representados existe, porém o canal de comunicação

Geografia Ensino \& Pesquisa, v. 18, n.3, p. $117-134$, set./dez. 2014

A representação e a representatividade social do Comitê de Bacia Hidrográfica dos Rios Vacacaí e Vacacaí-Mirim/RS utilizado não possibilita uma relação mais profunda com a maioria das pessoas que compõem a entidade de origem. A princípio os representantes não parecem ser representativos do conjunto de sua entidade, mas de alguns grupos dentro dele.

Entre os representantes, $75 \%$ coletam assuntos/opiniões junto às suas entidades de origem para serem utilizadas nas discussões do CBH. Todos os representantes da população da $\mathrm{BH}$ e $71 \%$ dos representantes dos usuários da água coletam assuntos e opiniões, no 
entanto o poder público não realiza essa coleta junto às suas instituições. A via de comunicação para essa finalidade, em 54\%, foi a conversa informal com pessoas pertencentes à entidade. Entre os representantes do setor dos usuários da água (50\%) e o setor da população da $\mathrm{BH}(50 \%)$ essa via foi a principal. Observa-se que os representantes estruturam sua ação no $\mathrm{CBH}$ baseados nos interesses da base, porém existem ressalvas sobre esses interesses serem do conjunto da base ou de alguns grupos dentro dela.

A coleta de assuntos e opiniões junto à base é relevante para que o representante saiba qual a posição da mesma sobre os assuntos a serem tratados pelo $\mathrm{CBH}$, pois eles não podem perder de vista que são representantes e devem defender os interesses da sua base e não os seus próprios. Dos três setores pode-se inferir que os representantes da população da $\mathrm{BH}$ e dos usuários da água são os mais representativos de sua base, pois buscam coletar assuntos/opiniões junto as suas bases. Enquanto isso, os representantes do setor do poder público não realizam essa atividade.

A maioria dos representantes (58\%) não possuem regras para atuar dentro do $\mathrm{CBH}$ em nome de suas entidades de origem. 57\% dos representantes dos usuários da água e $100 \%$ do poder público não possuem regras, já $50 \%$ dos representantes da população da $\mathrm{BH}$ possuem regras. Os representantes que possuem regras afirmaram, em $60 \%$, que elas são formais. Todos os representantes da população da $\mathrm{BH}$ afirmaram possuir regras formais, enquanto que $67 \%$ dos representantes dos usuários possuem regras informais. As regras sobre a atuação dos representantes formuladas por suas instituições de origem são consideradas mecanismos de controle desses representantes, assim garantindo que eles defendam os interesses da base. Nota-se que menos da metade dos representantes são controlados por suas bases, possuindo liberdade para participarem dos CBHs. No entanto, surgem dúvidas sobre se os representantes realmente defendem os interesses de sua base ou apenas os seus dentro dessa instância, devido à liberdade que possuem.

A postura utilizada pelos representantes nas discussões do CBH está baseada principalmente na utilização da opinião coletada e discutida na entidade de origem (64\%). Esse aspecto possui destaque nos três setores do $\mathrm{CBH}$, visto que o setor do poder público possui $100 \%$, o setor da população da BH com $80 \%$ e o setor dos usuários da água com $50 \%$ dos seus representantes com essa postura. Nesse contexto, para que um representante tenha representatividade de sua base, espera-se que ele defenda os interesses da mesma, por isso é necessário que eles construam junto à base uma posição e uma postura a ser sustentada nas discussões e tomada de decisões no CBH. Dessa forma, os mais representativos da base são os representantes do setor do poder público.

Todos os representantes afirmaram receber a pauta das reuniões com antecedência. Porém, $58 \%$ dos representantes não a discutem com a sua entidade de origem e essa tendência encontra-se presente nos três setores do CBH. As justificativas apresentadas para a não discussão da pauta foram: pautas com temáticas pouco interessantes à entidade de origem, o não interesse da instituição de origem em discutir as temáticas do $\mathrm{CBH}$ e o recebimento da pauta com pouco tempo de antecedência, o que inviabiliza a sua discussão com a base. A discussão das pautas é considerada um meio para a interação entre representantes e representados, pois permite ao representante conhecer a opinião da sua base sobre os assuntos a serem tratados no $\mathrm{CBH}$, podendo construir uma posição que seja compatível com os interesses da mesma. No entanto, no $\mathrm{CBH}$ pouco vem sendo desenvolvido a esse respeito.

Outro aspecto que qualifica a atuação dos representantes na defesa dos interesses da sua base no $\mathrm{CBH}$ é a interação e a estruturação de alianças entre os representantes que compartilham do mesmo posicionamento nos assuntos tratados nessa instância. Essas alianças contribuem para uma defesa mais efetiva dos interesses pelos representantes. No CBH ocorre essa interação, o que qualifica a defesa dos interesses das bases pelos

Geografia Ensino \& Pesquisa, v. 18, n.3 p. $117-134$, set./dez. 2014.

Meier, M.A.; Basso, L. A. 
representantes.

Dentro do CBH ocorre a interação entre os representantes, 83\% deles afirmaram realizá-la. Somente os representantes do setor do poder público não desenvolvem interações com outros representantes. A conversa informal foi apontada por $54 \%$ dos representantes como meio de interação entre eles. Esse meio é utilizado por $60 \%$ dos representantes do setor da população da $\mathrm{BH}$, e os representantes do setor dos usuários encontram-se divididos entre reunião formal e conversa informal (50\% cada um).

Essa interação ocorre principalmente pelo interesse dos representantes em realizá-la, sendo que $70 \%$ deles apontaram essa resposta, havendo pouca interferência da entidade de origem como incentivadora da mesma. Apenas 17\% dos representantes identificaram problemas para a interação entre os representantes e o motivo apresentado é a falta de tempo para tal atividade.

Outros indicadores também podem ser utilizados para a caracterização da representatividade dos representantes do CBH, como: os conhecimentos sobre o seu papel no CBH e sobre o funcionamento dessa instância; experiência dentro do $\mathrm{CBH}$ e com a realidade da $\mathrm{BH}$; qualificação política e técnica; acesso a informações, entre outros. Esses indicadores permitem aos representantes atuar de maneira efetiva no processo de negociação dentro do $\mathrm{CBH}$ e defender os interesses da sua base de forma igualitária, partilhando o poder decisório entre os representantes. Entre os aspectos que caracterizam positivamente a representatividade dos representantes no CBH V-VM estão: o conhecimento sobre a história do $\mathrm{CBH}$, a ampla experiência que possuem na BH, e a participação em atividades de capacitação, o que garante a sua qualificação.

$\mathrm{O} \mathrm{CBH}$ possui 15 anos de existência e seus representantes participam do mesmo em períodos de tempo bastante diversificados, com predomínio do período entre zero e quatro anos $(50 \%)$, principalmente do setor da população da $\mathrm{BH}(50 \%)$ e do setor do poder público $(100 \%)$. Esses representantes participam do CBH a pouco tempo, tendo pouca experiência nas atividades dessa instância. Já o setor dos usuários da água possui a maior parcela de representantes que participam do $\mathrm{CBH}$ a mais tempo, entre 8 e 15 anos (43\%). Com isso nota-se que os representantes mais novos dentro do $\mathrm{CBH}$ correm o risco de terem sua participação prejudicada por possuírem pouco conhecimento sobre o funcionamento desse espaço, sendo facilmente influenciados pelos representantes mais experientes. Assim, os representantes dos usuários possuem vantagens sobre os representantes da população da $\mathrm{BH}$ e do poder público, quanto à sua atuação dentro do $\mathrm{CBH}$.

Entre os representantes, 83\% foram chamados a fazer parte do CBH por sua entidade de origem e 17\% iniciaram a participação por interesse próprio, levando à procura da entidade de origem para tornar-se representante da mesma. No setor dos usuários $86 \%$ e no setor da população da $\mathrm{BH} 75 \%$ foram chamados pela entidade para participarem do $\mathrm{CBH}$, enquanto que $100 \%$ dos representantes do poder público iniciaram a participação por interesse próprio. Pode-se inferir que os setores dos usuários e da população da $\mathrm{BH}$ encontram-se representados no $\mathrm{CBH}$ pelo interesse das instituições, que escolheram seus próprios representantes. Já no setor do poder público a iniciativa não é da instituição, mas sim de pessoas interessadas em participar do CBH. Isso demonstra o desinteresse desse setor em participar do CBH. Nesse contexto, surgem indagações sobre se o representante escolhido pelas instituições é apropriado para representá-los, e se as pessoas que procuraram as entidades para tornarem-se seus representantes são representativas dessa base.

A maior parte dos representantes (83\%) possui conhecimento sobre a história do
A representação e a representatividade social do Comitê de Bacia Hidrográfica dos Rios Vacacaí e Vacacaí-Mirim/RS
Geografia Ensino \& Pesquisa, v. 18, n.3, p. 117-134, set./dez. 2014. CBH. Todos os representantes da população da BH e 86\% dos usuários da água afirmaram possuir esse conhecimento, enquanto o setor do poder público não o possui. Essas informações foram disponibilizadas principalmente pelos CBHs, 54\% dos representantes apontaram essa fonte. Nenhum representante apontou os meios de comunicação 
como fontes dessas informações, isso porque quase não se encontram notícias sobre o $\mathrm{CBH}$ nesses meios.

$\mathrm{O} \mathrm{CBH}$ tem $75 \%$ de seus representantes morando a mais de 20 anos na $\mathrm{BH}$, visto que $100 \%$ dos representantes do setor dos usuários e da população da $\mathrm{BH}$ moram a mais de 10 anos na $\mathrm{BH}$. Já o poder público possui menor tempo de moradia na $\mathrm{BH}$, todos moram a menos de 5 anos. Os setores dos usuários da água e da população da $\mathrm{BH}$ possuem representantes com maior conhecimento e experiência sobre a realidade vivenciada pela $\mathrm{BH}$. Pode-se inferir que os representantes possuem uma ampla vivência com o seu espaço cotidiano, o que facilita (re)conhecer as principais problemáticas que envolvem o uso dos recursos hídricos. A experiência dos representantes contribui para uma tomada de decisão baseada na realidade da $\mathrm{BH}$, tendo assim maior probabilidade de êxito na implementação dessas decisões. Dessa forma, os representantes atuam de forma qualificada dentro do $\mathrm{CBH}$.

Dos representantes $83 \%$ participam de atividades de capacitação, com destaque para os representantes da população da BH (100\%) e dos usuários da água (86\%), no entanto os representantes do poder público não participam dessas atividades. As principais atividades de capacitação que os representantes participam são: as palestras promovidas pelo $\mathrm{CBH}$ $(27 \%)$ e as atividades de educação ambiental (27\%). Essas duas atividades prevalecem no setor da população da $\mathrm{BH}$ ( $37 \%$ cada um) e no setor dos usuários da água ( $22 \%$ cada um).

Os CBHs são espaços de negociação que possuem como objetivo realizar a gestão integrada dos recursos hídricos com outros planejamentos da $\mathrm{BH}$ em diversas áreas, por isso os CBHs não podem permanecer isolados dos espaços que tratam desses planejamentos. Entretanto, não pode-se perder de vista que a BH está integrada com outras BHs, por isso o CBH deve articular-se também com espaços participativos fora deste recorte espacial. Essa integração contribui para a troca de experiências e a estruturação de planejamentos e ações articuladas, o que fortalece esses espaços e torna-os mais eficazes no alcance de seus objetivos. Um dos caminhos que podem ser trilhados para que essa articulação ocorra é mediante a participação dos representantes do $\mathrm{CBH}$ em outros espaços participativos, dentro e fora da $\mathrm{BH}$, como em outros $\mathrm{CBH}$. Com isso, é possível destacar a possibilidade dos representantes em estruturar alianças com outros atores sociais e fortalecer a defesa dos interesses da sua base junto à plenária do $\mathrm{CBH}$.

Observa-se que os representantes do $\mathrm{CBH}$ não possuem uma participação expressiva em outros $\mathrm{CBH}$ s e espaços participativos fora da $\mathrm{BH}$, porém a maioria participa de espaços participativos dentro da $\mathrm{BH}$. Consequentemente as chances de estruturar um planejamento integrado dos recursos hídricos com outros espaços fora da $\mathrm{BH}$ são dificultados, mas o planejamento integrado dos $\mathrm{RH}$ com outros planejamentos dentro da $\mathrm{BH}$ parecem estar garantidos. Dessa forma, a defesa qualificada dos interesses das bases representadas no $\mathrm{CBH}$ por seus representantes amplia-se significativamente.

Os representantes em 83\% não participam de outros CBHs. Apenas 29\% dos representantes dos usuários afirmaram participar. Além do CBH V-VM eles pertencem também ao $\mathrm{CBH}$ do rio Pardo e do $\mathrm{CBH}$ do rio Ibicuí.

Entre os representantes $67 \%$ possuem participação em outros espaços dentro da $\mathrm{BH}$, e 33\% possuem participação em espaços fora da $\mathrm{BH}$. Os representantes do setor da população da $\mathrm{BH}$ foram os que mais participaram de espaços dentro da $\mathrm{BH}(75 \%)$ e os representantes do setor dos usuários da água foram os que mais participaram de espaços fora da $\mathrm{BH}(43 \%)$. Os representantes do setor do poder público não participaram de nenhum espaço participativo.

Os principais espaços que os representantes participam dentro da BH são: entidades profissionais $(31 \%)$ e os conselhos de meio ambiente $(25 \%)$, com destaque para o setor da população da BH (cada um com 33\%). Fora da BH os principais espaços parti-

Geografia Ensino \& Pesquisa, v. 18, n.3 p. 117-134, set./dez. 2014.

Meier, M.A.; Basso, L. A. 
cipativos que os representantes participam são os sindicatos (40\%), com destaque para os representantes do setor dos usuários da água (50\%); e os representantes da população participam do CREA (100\%).

Os representantes apontaram como principais motivos que dificultam a representatividade no CBH: a falta de informações disponíveis aos representantes $(20 \%)$, a falta de capacitação teórica e técnica dos representantes $(20 \%)$ e a falta de resultados práticos e concretos atingidos pelo CBH (20\%). No setor dos usuários 30\% dos representantes destacaram como principal justificativa a falta de capacitação teórica e técnica. No setor da população da $\mathrm{BH} 50 \%$ citaram a falta de resultados práticos do $\mathrm{CBH}$, e no setor do poder público 100\% afirmaram ser a falta de informações disponíveis.

São aparentemente contraditórias as respostas apresentadas ao longo do texto com as da última questão apresentada sobre a representatividade. Os representantes mesmo possuindo um nível de formação alto e participando de atividades de capacitação, a falta de informações disponíveis e a capacitação teórica e técnica são apontadas como obstáculos a sua representatividade. Isso pode ocorrer, pois as informações que estão sendo disponibilizadas não estão contribuindo significativamente para a atuação dos representantes no $\mathrm{CBH}$, não possibilitando a defesa dos interesses de suas bases com qualidade. Diante disso, faz-se necessário observar os outros problemas que acometem esses aspectos e propor alternativas para que sejam mais eficazes.

Em resumo, pode-se afirmar que os representantes do $\mathrm{CBH}$ possuem representatividade, porque conhecem e têm as condições necessárias para defender os interesses das suas bases com qualidade. Os aspectos que demonstram essa representatividade são: todos os representantes interagem com as suas bases a fim de tratar de assuntos do $\mathrm{CBH}$; ocorre a coleta de assuntos e opiniões pelos representantes nas entidades de origem sobre os assuntos discutidos no $\mathrm{CBH}$; a postura utilizada pelos representantes nas discussões do CBH está embasada na opinião coletada e discutida com a base; existe interação entre os representantes do $\mathrm{CBH}$; e os representantes possuem características que colaboram com a defesa dos interesses da sua base. Os setores que possuem representatividade mais significativa de sua base são os representantes da população da BH e dos usuários da água, o poder público é o menos representativo.

\section{Considerações finais}

Ao analisar os indicadores da representação e da representatividade dos representantes do CBH V-VM, observou-se que a representação encontra-se comprometida, não garantindo que todos os segmentos envolvidos com a questão das águas estejam equitativamente presentes nesses espaços. Porém, os representantes que encontram-se no $\mathrm{CBH}$ são representativos da sua base e possuem condições que possibilitam defender os interesses da mesma com qualidade.

Entre os setores que compõem o CBH identificou-se que o setor que possui maiores

Geografia Ensino \& Pesquisa, v. 18, n.3, p. 117-134, set./dez. 2014.

A representação e a representatividade social do Comitê de Bacia Hidrográfica dos Rios Vacacaí e Vacacaí-Mirim/RS dificuldades para que sua representação esteja garantida e que seus representantes sejam representativos é o poder público. Já o setor dos usuários da água e da população da BH são os que menos possuem problemas para garantir a sua representação e são os mais representativos no $\mathrm{CBH}$.

Observou-se que o CBH V-VM possui diversas problemáticas que acometem a sua representação e representatividade dos seus representantes. Faz-se necessário analisar mais profundamente essas problemáticas, a fim de melhor compreendê-las e estabelecer alter- 
nativas para minimizá-las. Diante disso, pode-se verificar que outros estudos se fazem necessários sobre a temática da representação e representatividade social dos $\mathrm{CBHs}$, principalmente quanto à sua interferência sobre as decisões tomadas nessa instância e as suas consequências sobre a (re)organização do espaço da bacia hidrográfica.

\section{Referências}

AGÊNCIA NACIONAL DE ÁGUAS. O comitê de Bacia Hidrográfica: o que é e o que faz? Brasília: SAG, 2011.

ARNSTEIN, S. A ladder of citizen participation. JAIP, v. 35, n. 4, p. 216-224, july, 1969.

BRASIL. Lei n. 9.433, de 8 de janeiro de 1997. Institui a Política Nacional de Recursos Hídricos. Disponível em: <http://www.planalto.gov.br/ccivil_03/leis/L9433.htm>. Acesso em: 20 dez. 2012.

DEMO, P. Participação é conquista: noções de política social participativa. São Paulo: Cortez, 2001.

FONT, J.; BLANCO, I.; GOMÀ, R.; JARQUE, M. Mecanismos de participación ciudadana en la toma de decisiones locales: una visión panorámica. In: XIV CONCURSO DE ENSAYOS DEL CLAD “ADMINISTRACIÓN PÚBLICA Y CIUDADANÍA, Caracas, 2000. Anais..., Caracas, 2000.

FRACALANZA, A. P. Gestão das águas no Brasil: rumo a governança da água? In.: RIBEIRO, W. C. (Org.) Governança da água no Brasil: uma visão interdisciplinar. São Paulo: Annablume, 2009.

FRANK, B. Formação e experiência: os organismos de bacia hidrográfica são capazes de lidar com a complexidade da gestão dos recursos hídricos? In: ABERS, R. N. (Org.) Água e política: Atores, instituições e poder nos organismos colegiados de bacia hidrográfica no Brasil. São Paulo: Annablume, 2010.

FREITAS, H.; OLIVEIRA, M.; SACCOL, A. Z.; MOSCAROLA, J. O método de pesquisa survey. Revista de Administração, São Paulo, v.35, n.3, jul/set, 2000.

GRANJA, S. I. B. Governança e governabilidade da água: assertiva e contradições. In: IV ENCONTRO NACIONAL DA ANPPAS, Brasília, 2008. Anais..., Brasília, 2008.

JACOBI, P. Apresentação. In: RIBEIRO, W. C. Geografia política da água. São Paulo: Annablume, 2008. $162 \mathrm{p}$.

. Governança da água no Brasil. In: RIBEIRO, W. C. (Org.) Governança da água no Brasil: uma visão interdisciplinar. São Paulo: Annablume, 2009.

LEAL, M. L. M. Representatividade e legitimidade da participação da sociedade civil no Conselho Municipal de Assistência Social. Porto Alegre: Pontifícia Universidade Católica do Rio Grande do Sul, 2003.

MACHADO, C. J. S. Recursos Hídricos e Cidadania no Brasil: limites, alternativas e desafios. Sociedade e Ambiente, v. VI, n. 2, p. 121-136, jul/dez, 2003. Disponível em: <http://www.scielo.br/pdf/asoc/v6n2/ a08v06n2.pdf >. Acesso em: 20 jun. 2012.

MEIER, M. A.; BASSO, L. A. A representação e representatividade social dos Comitês de Bacia Hidrográfica: indicadores para a análise. Revista Sociedade \& Natureza, (em avaliação).

MELHORAMENTOS. Michaelis: moderno dicionário da língua portuguesa. São Paulo: Melhoramentos, 2012.

MODESTO, P. Participação popular na administração pública: mecanismos de operacionalização. JusVigilantibus, Vitória, 1999.

MOREIRA, L. F. F.; GASKIN, S.; ADAMOWISKI, J. Gestão e governança dos recursos hídricos - os desafios da implementação. In: XX SIMPÓSIO NACIONAL DE RECURSOS HÍDRICOS, Bento Gonçalves, 2013. Anais..., Bento Gonçalves, 2013.

NEDER, R. T. Crise socioambiental: Estado \& Sociedade civil no Brasil (1982-1998). São Paulo: Annablume, 2002.

Geografia Ensino \& Pesquisa, v. 18, n. 3 p. $117-134$, set./dez. 2014

Meier, M.A.; Basso, L. A. 
NEVES, J. L. Pesquisa qualitativa: características, usos e possibilidades. Cadernos de Pesquisas em Administração, v. 1, n.3, 2 sem., 1996.

PITKIN, H. F. The concept of representation. Berkeley: University of California Press, 1967.

RIBEIRO, W. C. Governança da água no Brasil. In: RIBEIRO, W. C.(Org.) Governança da água no Brasil: uma visão interdisciplinar. São Paulo: Annablume, 2009.

RIO GRANDE DO SUL. Política Estadual de Recursos Hídricos. Lei n. 10.350, de 30 de dezembro de 1994. Disponível em: <http://www.al.rs.gov.br/site/ >. Acesso em: 20 out. 2009.

Decreto Estadual n ${ }^{\mathbf{0}} \mathbf{3 7 . 0 3 4}$, de 21 de novembro de 1996. Regulamenta o art. 18 da Lei no 10.350 de 1994. Disponível em:< http://www.al.rs.gov.br/legis/m010/M0100099.ASP?Hid_Tipo=TEXTO\&Hid_ TodasNormas=9943\&hTexto=\&Hid_IDNorma=9943>. Acesso em: 27 de jun. de 2013.

SAMPIERI, R. H.; COLLADO, C. F; LUCIO, P. B. Metodologia de pesquisa. $3^{\text {a }}$ ed. McGraw-Hill, 2006.

SANTOS, M. A natureza do espaço: técnica e tempo - razão e emoção. 3 ed. São Paulo: Hucitec, 1999.

SANTOS, I. A. dos; SAITO, C. H. A mitificação da participação social na política nacional de recursos hídricos: gênese, motivação e inclusão social. Geosul, Florianópolis, v. 21, n. 42, p. 7-27, jul/dez, 2006.

TEIXEIRA, E. C. Movimentos sociais e Conselhos. Cadernos Abong, n. 15, julho, 1996.

As dimensões da participação cidadã. Caderno CRH. Salvador: Universidade Federal da Bahia, v. 10, n. $26,1997$.

TERENCE, A. C. F.; FILHO, E. E. Abordagem quantitativa, qualitativa e a utilização da pesquisa-ação nos estudos organizacionais. In: XXVI Encontro Nacional de Engenharia da Produção - ENEGEP, Fortaleza, 2006. Anais..., Fortaleza, 2006.

VALÊNCIO, N. F. de L. da S. Governança das águas: a participação social como quimera. In: RIBEIRO, W. C.(Org.) Governança da água no Brasil: uma visão interdisciplinar. São Paulo: Annablume, 2009.

\section{Correspondência}

\section{Mara Alini Meier}

E-mail: mara.alini@gmail.com

Recebido em 17 de julho de 2014.

Revisado pelo autor em 17 de novembro de 2014.

Aceito para publicação em 28 de novembro de 2014. 